\title{
INFLUENCE OF HIGH-SPEED TRAIN POWER CONSUMPTION ON A NOVEL GROUND FAULT IDENTIFICATION METHOD FOR $2 \times 25$ KV RAILWAY POWER SUPPLY SYSTEMS
}

\author{
J. SERRANO, C.A. PLATERO, M. LÓPEZ-TOLEDO \& R. GRANIZO \\ Department of Electric Engineering, E.T.S.I. Industriales, Politechnical University of Madrid, Spain.
}

\begin{abstract}
Nowadays, the most commonly used configuration to supply high-speed trains is $2 \times 25 \mathrm{kV}$ power supply system. The location of ground faults in $2 \times 25 \mathrm{kV}$ power supply systems is a difficult task, since the use of distance protection relays to localize ground faults positions doesn't work properly as the relation between the distance and the impedance seen by the distance protection relays is not linear and therefore the location is not accurate enough. A new simple and economical method to identify the subsection between autotransformers (ATS) and the conductor (positive or negative) where the ground fault is happening, based on the comparison of the angle between the current and the voltage of the positive terminal in each autotransformer, was developed recently. Consequently, after the identification of the subsection and the conductor with the ground fault, only this subsection where the ground fault is present, will be quickly removed from service, with the minimum effect on rail traffic. The high-speed trains demand a power about 12-16 MW, hence a significant current flow through the conductors of the $2 \times 25 \mathrm{kV}$ power system. This paper presents a study about the influence of the current consumed by the high-speed trains on this novel ground fault identification method. The operation of the method is correct even with the high-speed train currents in the section with a ground fault. This fact has been validated through numerous computer simulations, obtaining excellent results.
\end{abstract}

Keywords: fault location, ground faults, protection, $2 \times 25 \mathrm{kV}$, railways.

\section{INTRODUCTION}

At present, the usual method of providing high levels of power to feed high-speed trains is a traction system called $2 \times 25 \mathrm{kV}$. This power supply system has a positive conductor (usually called catenary) at $25 \mathrm{kV}$ AC voltage with a positive polarity with respect to ground, and a negative voltage conductor (usually called feeder) at $25 \mathrm{kV}$ AC voltage with a negative polarity with respect to ground. The supply to the trains employs the catenary and the grounded rail.

In these power systems, the complete traction line is supplied by several traction substations (TS). Each TS supplies two sections. Moreover, in each section, there are several subsections at regular intervals which are delimited by stations with power ATS. At the end of each section another autotransformer station (SATS) is installed. In Fig. 1 a traction line section with three subsections is shown, as well as the theoretical current distribution.

In $2 \times 25 \mathrm{kV}$ power systems, the traction power demanded is delivered at $50 \mathrm{kV}$ while it is used at $25 \mathrm{kV}$. This fact reduces the current needed to supply the power required by highspeed trains [1]. In consequence, the length of the sections can be greater and the number of TS lower. 


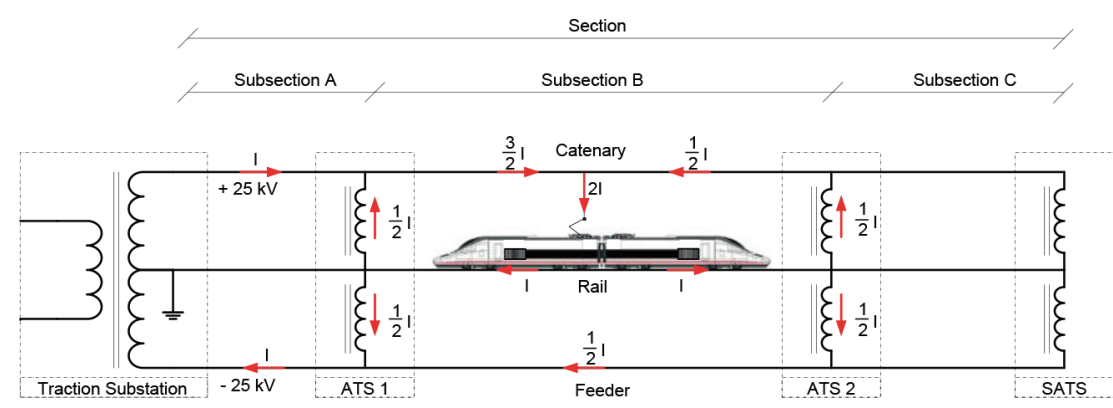

Figure 1: Simplified diagram of a $2 \times 25 \mathrm{kV}$ power system and currents distribution in a section comprising three subsections.

Another remarkable advantage of the $2 \times 25 \mathrm{kV}$ traction systems is the great reduction of electromagnetic interference on communication facilities and railway signalling circuits (signalling track circuits) as well as on nearby telecommunication lines [2, 3].

Railway traction systems have frequent external faults caused by accidental events. In the $2 \times 25 \mathrm{kV}$ power systems most of them are caused by outdoor short circuits between the catenary or the feeder to ground $[4,5]$. But in this system, the ratio between the impedance (Z) seen from the TS and the distance to the ground fault is non-linear because of the use of ATS. This ratio is as shown in Fig. $2[6,7]$. That is why it is so complex to use efficiently in the $2 \times 25 \mathrm{kV}$ lines the protection system based on distance protection relays [8].

This complexity of the detection and location of ground faults in the $2 \times 25 \mathrm{kV}$ lines means that the identification of the subsection and the conductor where the ground fault has happened $[6,9]$ is the main task of the protection systems in order to disconnect immediately the conductor with the ground fault in the corresponding subsection [10]. So only trains running in the subsection with the ground fault, in the case where the fault is in the catenary, will be disconnected from the power supply. Serrano et al. [11] describe a new method for identifying the subsection and the conductor (catenary or feeder) in which there is a ground fault in an easy and economical way. As the identification is done immediately, the subsection and conductor can be disconnected while keeping the rest of the power system in service. Besides, to implement this method, a small investment is required.

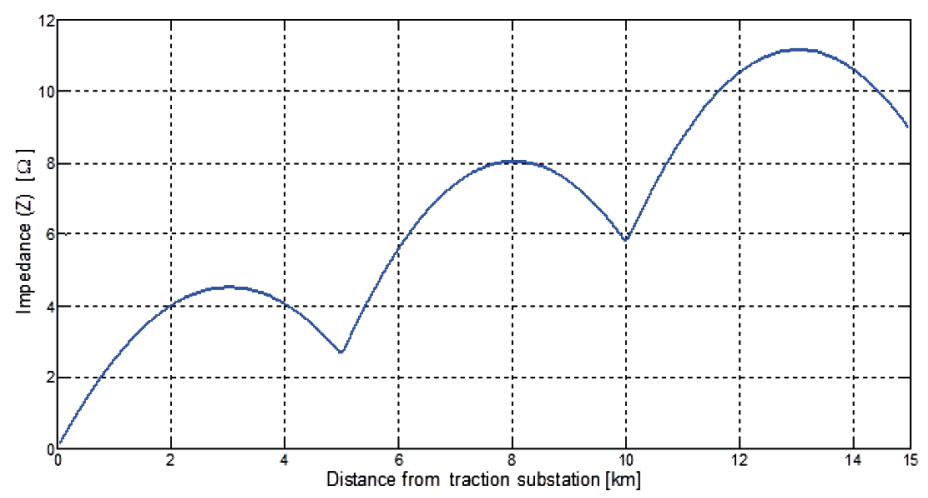

Figure 2: Modulus of the fault impedance seen from the traction substation in function of the distance in $2 \times 25 \mathrm{kV}$ traction power systems. 
This paper presents a study about the influence of the current consumed by the high-speed trains on this novel ground fault identification method. In Section 2 an overview of this identification method is presented. In Section 3 the influence of high-speed train power consumption on this novel ground fault identification method is analysed. Finally, in Section 4 conclusions are shown.

\section{GROUND FAULT IDENTIFICATION METHOD FOR $2 \times 25 \mathrm{KV}$ RAILWAY POWER SUPPLY SYSTEMS}

\subsection{Description of the method}

In normal operation of $2 \times 25 \mathrm{kV}$ traction power supply system, the phase angle between voltage and current in the autotransformer is close to $180^{\circ}$ (Fig. 3), according to the theoretical current distribution previously shown in Fig. 1 [11].

When there is a ground fault on a line between the catenary and rail or between the feeder and rail in a $2 \times 25 \mathrm{kV}$ traction power system, there is a substantial increase in the current circulating through the windings of the ATS closest to the defect location. This current increase can be detected easily by measuring the currents in the windings of the ATS. Furthermore, when the fault happens, the angles between the currents and voltages shift by $90^{\circ}$ in the ATS closest to the fault location. In the case of a ground fault between the catenary and rail, the phase angle between the voltage and current in these ATS will result in $90^{\circ}$ while in the case of ground fault between the feeder and rail, these angle will be $270^{\circ}$.

Figure 4 shows an example of a ground fault between catenary and rail in section B. In this particular case, the angles between $I_{\mathrm{A} 1}$ and $V_{\mathrm{C} 1}$ and between $I_{\mathrm{A} 2}$ and $V_{\mathrm{C} 2}$, respectively, change their values from approximately $180^{\circ}$ to $90^{\circ}$. Also, there is a great increase in the module of $I_{\mathrm{A} 1}$ and $I_{\mathrm{A} 2}$.
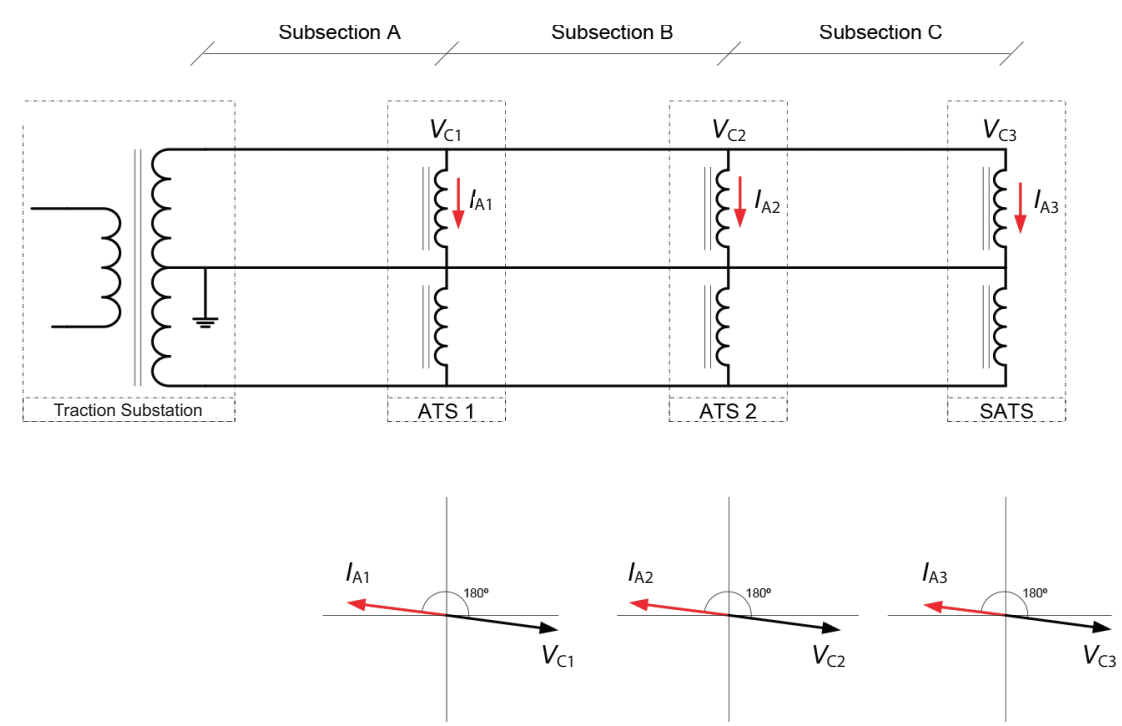

Figure 3: $2 \times 25 \mathrm{kV}$ power system currents $\left(I_{\mathrm{A}}\right)$ and voltages $\left(V_{\mathrm{C}}\right)$ distribution in normal operation. 


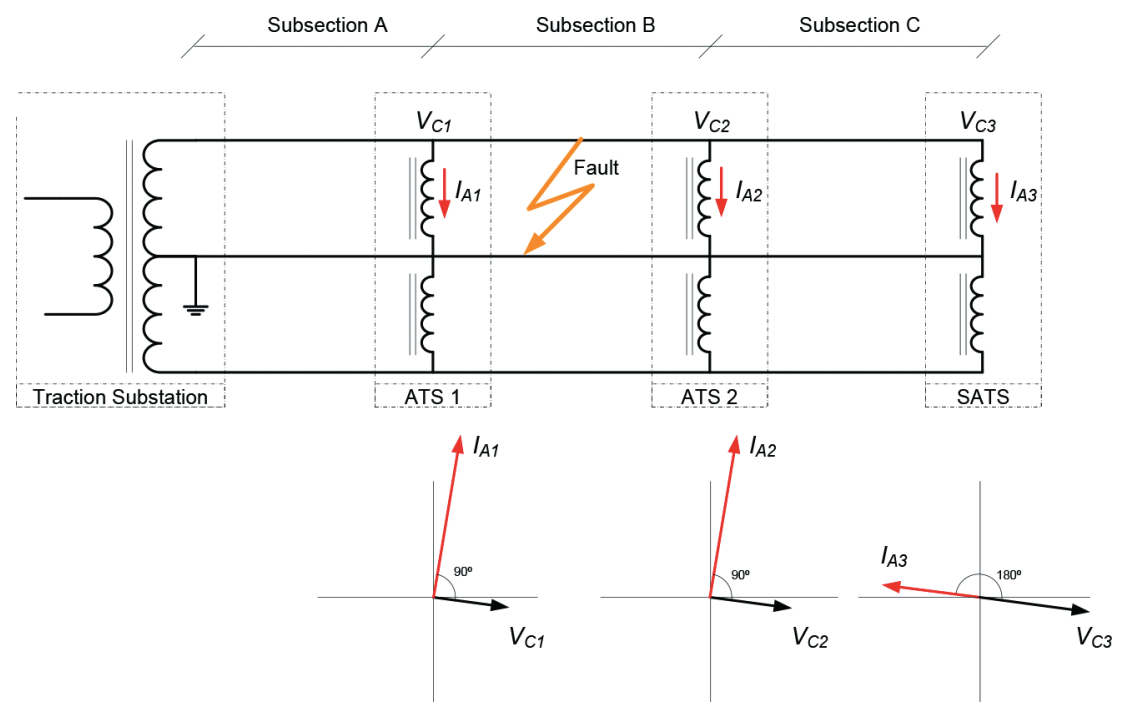

Figure 4: $2 \times 25 \mathrm{kV}$ power system currents $\left(I_{\mathrm{A}}\right)$ and voltages $\left(V_{\mathrm{C}}\right)$ distribution with a ground fault in the catenary in subsection B.

Another example can be seen in Fig. 5. It shows a ground fault between feeder and rail in section $\mathrm{C}$. The current increase in this case will affect only currents $I_{\mathrm{A} 2}$ and $I_{\mathrm{A} 3}$ and there will be no remarkable change in current $I_{\mathrm{A} 1}$. The angles between $I_{\mathrm{A} 2}$ and $V_{\mathrm{C} 2}$, and $I_{\mathrm{A} 3}$ and $V_{\mathrm{C} 3}$, respectively, will change, but not the angle between $I_{\mathrm{A} 1}$ and $V_{\mathrm{Cl}}$. These phase angle changes will be from $180^{\circ}$ to $270^{\circ}$.
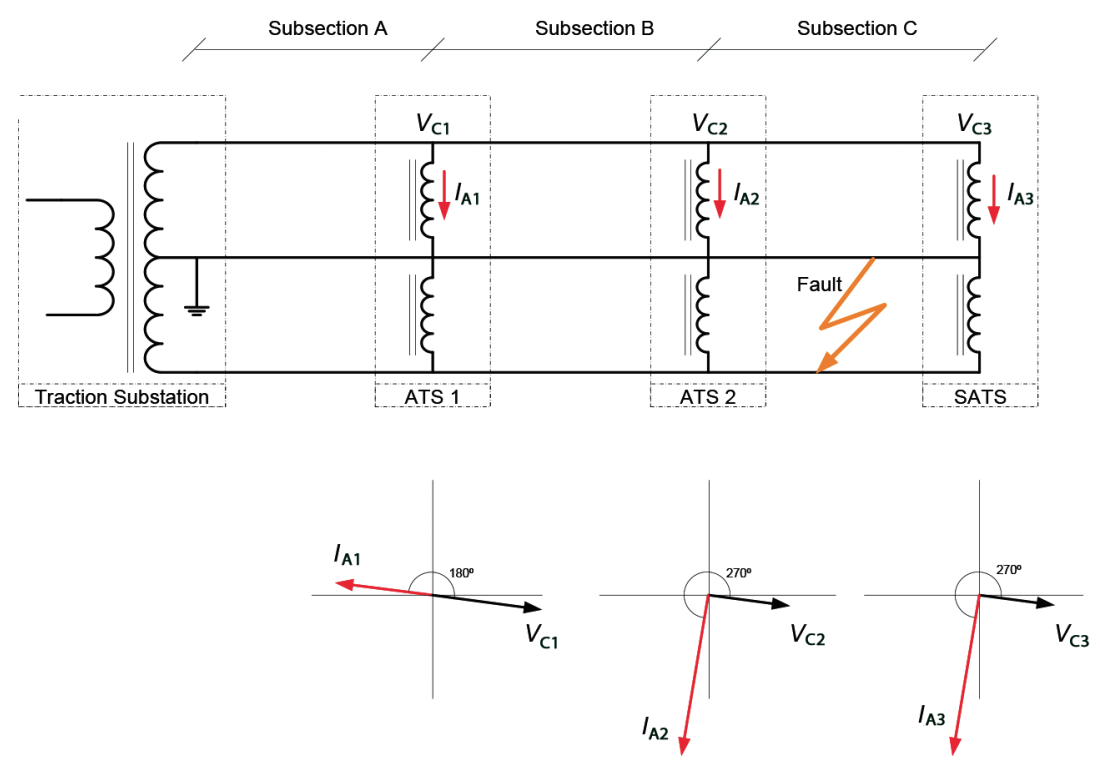

Figure 5: $2 \times 25 \mathrm{kV}$ power system currents $\left(I_{\mathrm{A}}\right)$ and voltages $\left(V_{\mathrm{C}}\right)$ distribution with a ground fault in the feeder in subsection $\mathrm{C}$. 
Table 1: Angle variation between $I_{\mathrm{A}}$ and $V_{\mathrm{C}}$ as a function of the subsection with the ground fault.

\begin{tabular}{lrrr}
\hline & ATS1 & ATS2 & ATS3 \\
\hline Fault at catenary in subsection 1 & $\mathbf{9 0}^{\circ}$ & $180^{\circ}$ & $180^{\circ}$ \\
Fault at feeder in subsection 1 & $\mathbf{2 7 0}^{\circ}$ & $180^{\circ}$ & $180^{\circ}$ \\
Fault at catenary in subsection 2 & $\mathbf{9 0}^{\circ}$ & $\mathbf{9 0}^{\circ}$ & $180^{\circ}$ \\
Fault at feeder in subsection 2 & $\mathbf{2 7 0}^{\circ}$ & $\mathbf{2 7 0}^{\circ}$ & $180^{\circ}$ \\
Fault at catenary in subsection 3 & $180^{\circ}$ & $\mathbf{9 0}^{\circ}$ & $\mathbf{9 0}^{\circ}$ \\
Fault at feeder in subsection 3 & $180^{\circ}$ & $\mathbf{2 7 0}^{\circ}$ & $\mathbf{2 7 0}^{\circ}$ \\
\hline
\end{tabular}

The changes of the angle between the currents and voltages when there is a ground fault in the system represented in Fig. 3 are listed in Table 1.

In this way, measuring the $I_{\mathrm{A}}$ module and the phase angle between $V_{\mathrm{C}}$ and $I_{\mathrm{A}}$, it is possible to know the subsection and the conductor where the ground fault has happened.

\subsection{Simulation model}

In order to validate the new method [11] numerous computer simulations have been carried out using modified nodal circuit analysis method ran on MATLAB ${ }^{\circledR}$ software applied to the circuit shown in Fig. 6.

The experimental circuit is supplied from one end with two $25 \mathrm{kV}$ AC sources with reverse polarity in each one. This circuit has three subsections A, B and C, each with a length of $10 \mathrm{~km}$.

Self and mutual impedances values used in the simulations are listed in Table 2.

Table 2: Self and mutual impedances values of the railway conductors.

\begin{tabular}{lcclll}
\hline \multicolumn{2}{c}{ Conductor } & Impedance $[\Omega / \mathrm{km}]$ & Conductor & & Impedance $[\Omega / \mathrm{km}]$ \\
\hline Catenary & $\mathrm{Z}_{\mathrm{C}}$ & $0.1197+\mathrm{j} 0.6224$ & Catenary-feeder & $\mathrm{Z}_{\mathrm{CF}}$ & $0.0480+\mathrm{j} 0.3401$ \\
Feeder & $\mathrm{Z}_{\mathrm{F}}$ & $0.1114+\mathrm{j} 0.7389$ & Catenary-rail & $\mathrm{Z}_{\mathrm{CR}}$ & $0.0491+\mathrm{j} 0.3222$ \\
Rail & $\mathrm{Z}_{\mathrm{R}}$ & $0.0637+\mathrm{j} 0.5209$ & Feeder-rail & $\mathrm{Z}_{\mathrm{FR}}$ & $0.0488+\mathrm{j} 0.2988$ \\
\hline
\end{tabular}

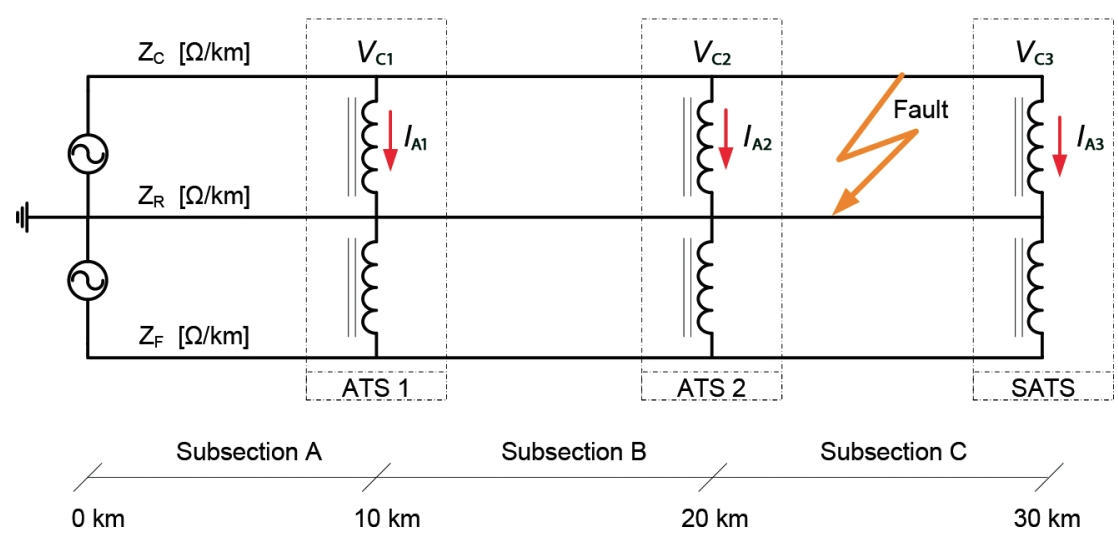

Figure 6: Simulated $2 \times 25 \mathrm{kV}$ power supply system. 

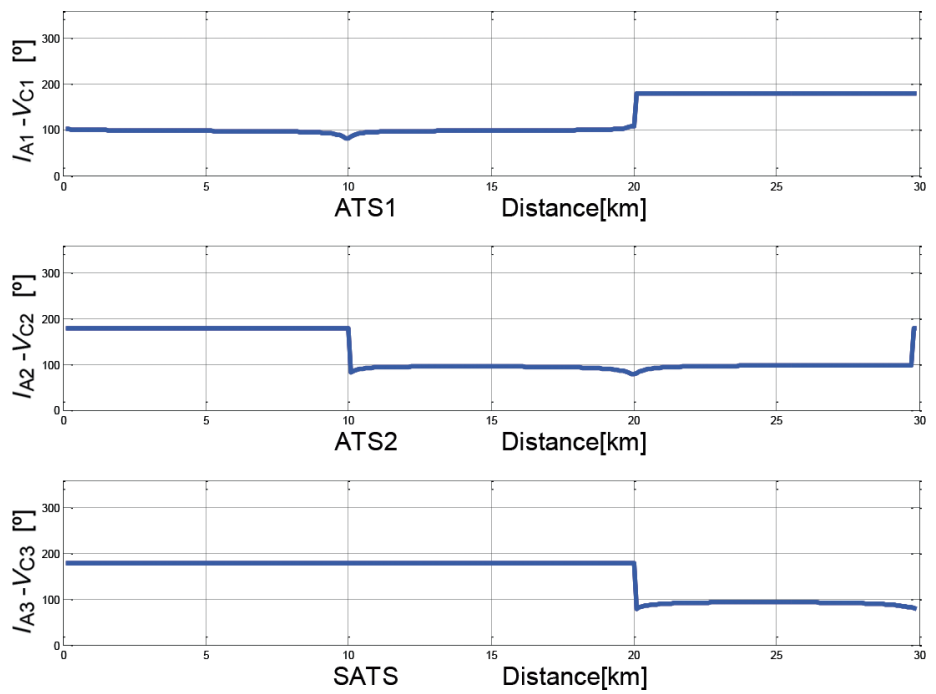

Figure 7: Phase angles between $I_{\mathrm{A}}$ and $V_{\mathrm{C}}$ at different ATS. Fault between catenary and rail.

Employing this circuit, different MATLAB ${ }^{\circledR}$ simulations were developed, performing short circuits between the catenary and rail, and between the feeder and rail. These short circuits were simulated at all the points along the three subsections A, B and C of the $30 \mathrm{~km}$ section. The phase angles between the currents $I_{\mathrm{A} 1}-I_{\mathrm{A} 2}-I_{\mathrm{A} 3}$ and the voltages $V_{\mathrm{Cl}}-V_{\mathrm{C} 2}-V_{\mathrm{C} 3}$ in the ATS ATS1, ATS2 and SATS, as a function of the distance from the TS where the fault has happened between the catenary and rail, are represented in Fig. 7. The axes used in Fig. 7 are scaled from 0 to $30 \mathrm{~km}$ and from $0^{\circ}$ to $360^{\circ}$. It can be observed that if the fault happens in subsection A along the first $10 \mathrm{~km}$, the angle between the current $I_{\mathrm{A} 1}$ and voltage $V_{\mathrm{C} 1}$ in the ATS1 is about $90^{\circ}$. However, such angles at ATS2 and SATS are $180^{\circ}$. Likewise, if the fault is in subsection $\mathrm{B}$ (between 10 and $20 \mathrm{~km}$ ) the phase angles between the current $I_{\mathrm{A} 1}$ and the voltage $V_{\mathrm{Cl}}$, and between the current $I_{\mathrm{A} 2}$ and the voltage $V_{\mathrm{C} 2}$, will be about $90^{\circ}$ at both ATS1 and ATS2, while at SATS this angle is close to $180^{\circ}$. It can also be seen that if the fault is in subsection $\mathrm{C}$ (between 20 and $30 \mathrm{~km}$ ), the angle is about $90^{\circ}$ at ATS2 and SATS but $180^{\circ}$ at ATS 1.

In the case where the fault happens between the feeder and rail, the results obtained are similar when the fault takes place between the catenary and rail, except that now the angles between the currents $I_{\mathrm{A} 1}-I_{\mathrm{A} 2}-I_{\mathrm{A} 3}$ and the voltages $V_{\mathrm{C} 1}-V_{\mathrm{C} 2}-V_{\mathrm{C} 3}$ are $270^{\circ}$ instead of $90^{\circ}$. Figure 8 shows how the variations of these phase angles as a function of the distance to the fault from the substation follow the same pattern as in the case of a fault between the catenary and rail, but now with values close to $270^{\circ}$.

\section{INFLUENCE OF HIGH-SPEED TRAIN POWER CONSUMPTION ON THIS NOVEL GROUND FAULT IDENTIFICATION METHOD}

In order to study the influence of the train consumption in the operation of the new identification method, a current source has been added to the circuit previously shown in Fig. 6. The current $I$ considered is 616 A with a 0.95 power factor, which represents a high-speed train consumption during the acceleration process. In this case, the current source is placed in the midpoint of the subsection B in Fig. 9, but different train locations have been studied. 

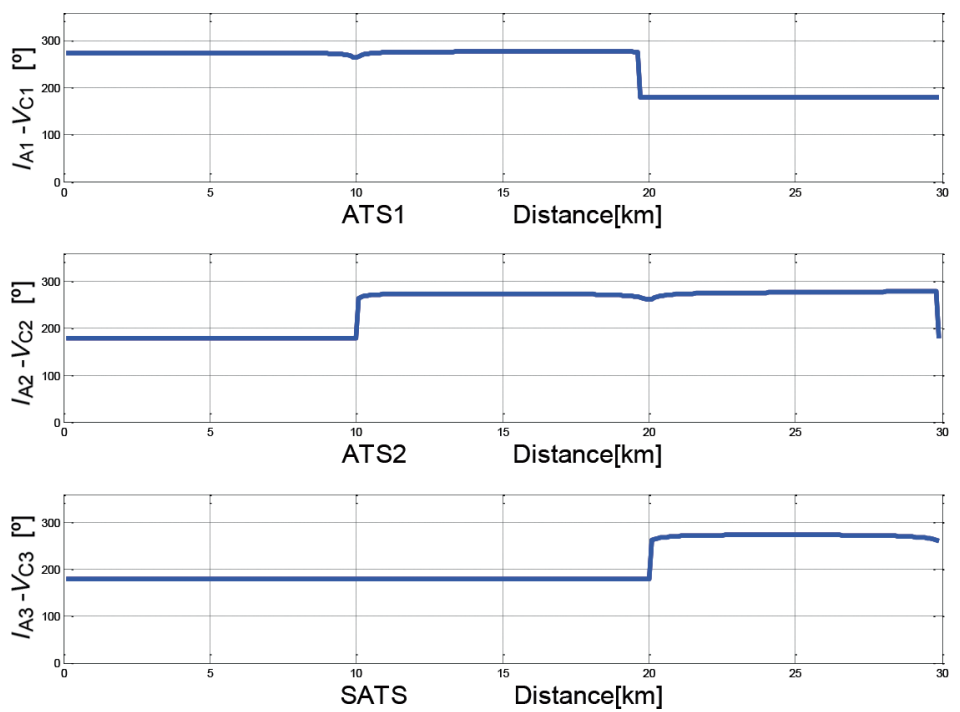

Figure 8: Phase angles between $I_{\mathrm{A}}$ and $V_{\mathrm{C}}$ at different ATS. Fault between feeder and rail.

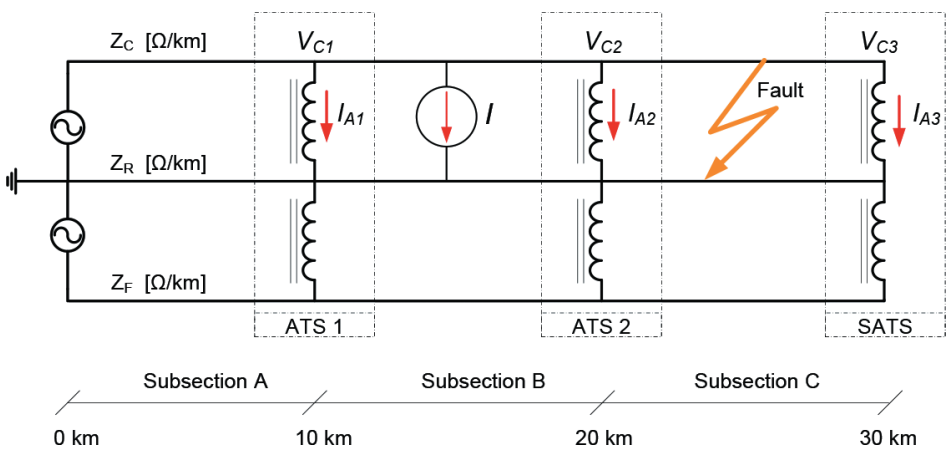

Figure 9: Simulated $2 \times 25 \mathrm{kV}$ power supply system including a train.

New MATLAB ${ }^{\circledR}$ simulations were developed on this modified circuit, performing short circuits between the catenary and rail, and between the feeder and rail. These short circuits were simulated at all points along the three subsections $\mathrm{A}, \mathrm{B}$ and $\mathrm{C}$ of the $30 \mathrm{~km}$ section, including the presence of one or two trains in the middle of $\mathrm{A}, \mathrm{B}$ and $\mathrm{C}$ subsections. In this way, the phase angles between the currents $I_{\mathrm{A} 1}-I_{\mathrm{A} 2}-I_{\mathrm{A} 3}$ and the voltages $V_{\mathrm{C} 1}-V_{\mathrm{C} 2}-V_{\mathrm{C} 3}$ in the ATS ATS1, ATS2 and SATS, as a function of the distance from the traction substation, are obtained when a ground fault has happened.

Among all the simulations performed, several results are presented in this section as example.

The phase angles in case of short circuit between catenary and rail are shown in Fig. 10, including a train in the midpoint of subsection B. 

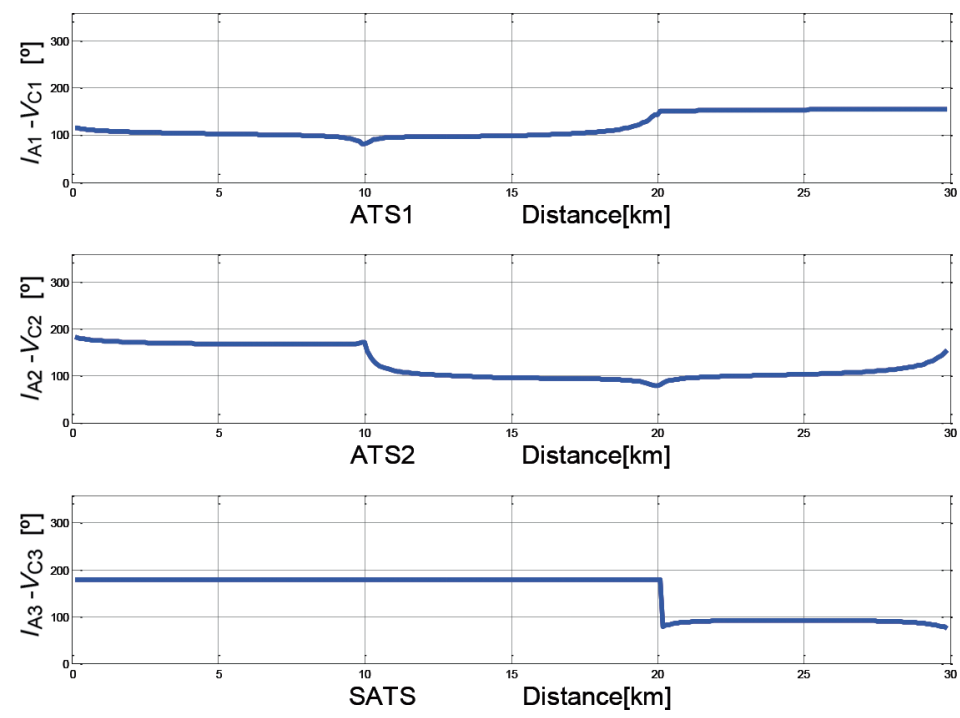

Figure 10: Phase angles between $I_{\mathrm{A}}$ and $V_{\mathrm{C}}$ at different ATS. Fault between catenary and rail. A train is simulated at the middle point of subsection $\mathrm{B}$.

In case of short-circuit between feeder and rail, the results are represented in Fig. 11. In this case the train is placed at the midpoint of the subsection A.

The results in case of two trains in the same section are shown in Figs 12 and 13.

In Fig. 12 the short circuits considered are catenary-rail, and the trains are placed in the subsections $\mathrm{A}$ and $\mathrm{B}$, respectively.

In Fig. 13 the case corresponds to short circuits between feeder and rail with two trains in the subsections $\mathrm{A}$ and $\mathrm{C}$.
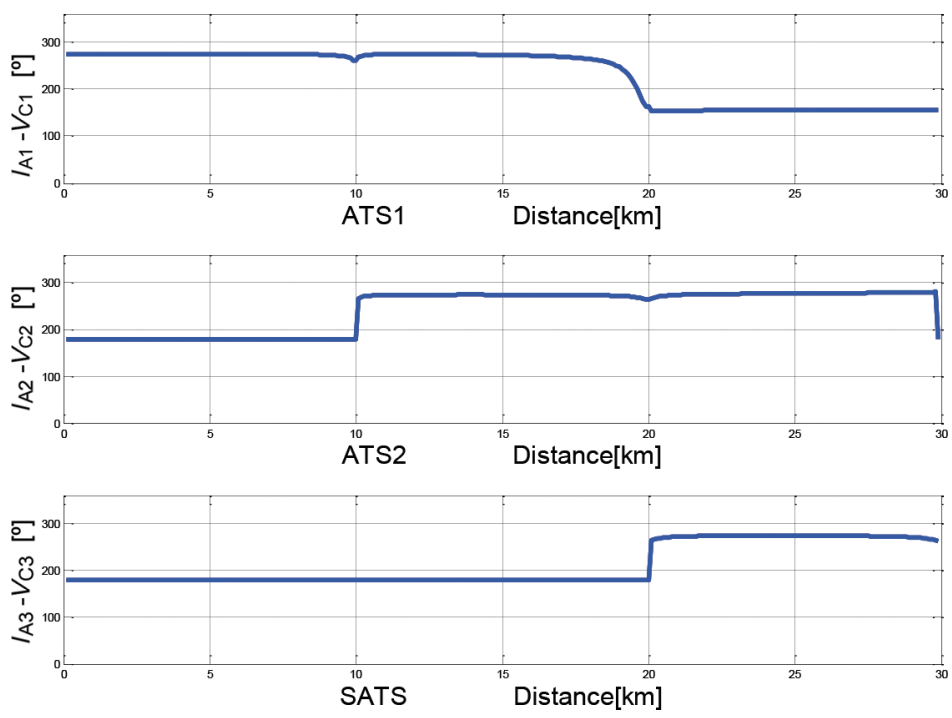

Figure 11: Phase angles between $I_{\mathrm{A}}$ and $V_{\mathrm{C}}$ at different ATS. Fault between feeder and rail. A train is simulated at the middle of subsection A. 

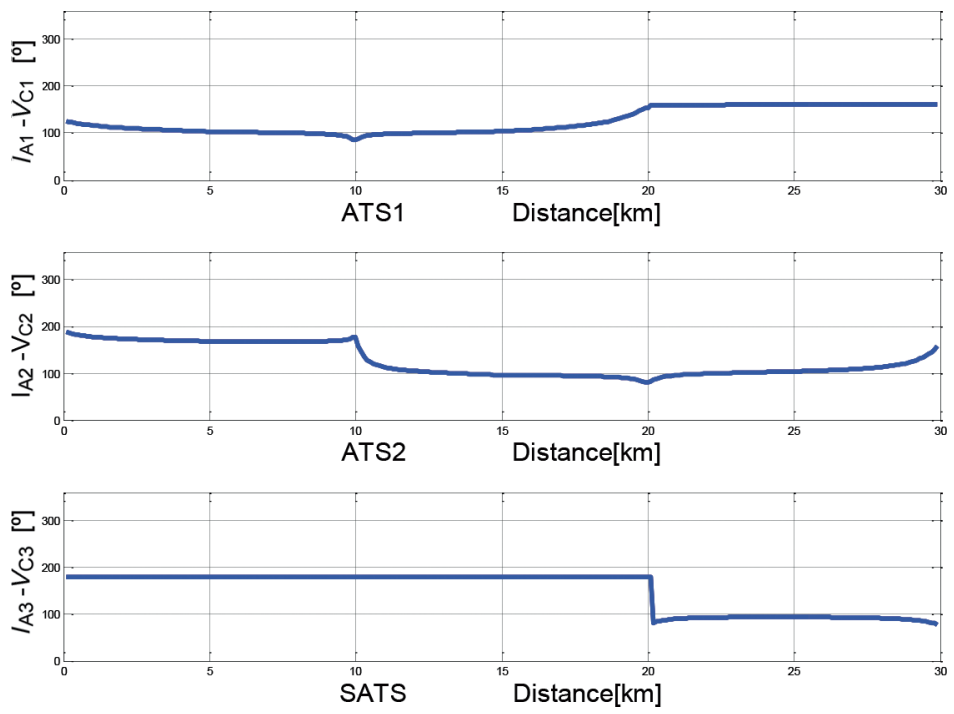

Figure 12: Phase angles between $I_{\mathrm{A}}$ and $V_{\mathrm{C}}$ at different ATS. Fault between catenary and rail. Two trains are placed at subsections A and B.
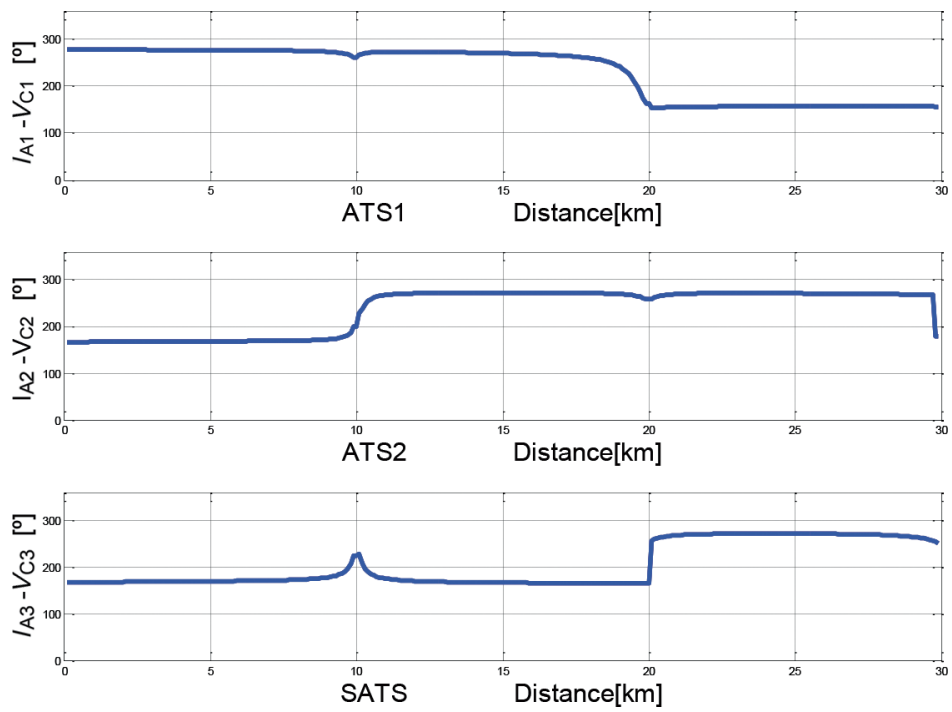

Figure 13: Phase angles between $I_{\mathrm{A}}$ and $V_{\mathrm{C}}$ at different ATS. Fault between feeder and rail. Two trains are placed at subsections $\mathrm{A}$ and $\mathrm{C}$.

\section{CONCLUSIONS}

The influence of the high-speed trains consumption has been studied in the operation of a novel ground fault location method.

For this purpose a computer simulation model has been developed. Numerous simulations have been performed including one and two trains in the same section doing short circuits in the catenary and feeder along the $30 \mathrm{~km}$ of the section. 


\section{COMPRAIL}

Although the power consumed by the high-speed trains slightly modify the theoretical $90^{\circ}$ phase shift in case of ground fault, according to the results of all the simulations performed, the operation of the new ground fault identification method is correct, as long as the characteristic angle setting (previously set to $\pm 30^{\circ}$ ) of the directional overcurrent protection relay is properly modified [11]. The new value of the setting depends on the electrical section to be protected.

\section{REFERENCES}

[1] Pilo, E., Rouco, R. \& Fernandez, A., A reduced representation of $2 \times 25 \mathrm{kV}$ electrical systems for high-speed railways. Proceedings of the 2003 IEEE/ASME Joint Rail Conference. Chicago, IL, pp. 199-205, 2003.

[2] Courtois, C., Why the $2 \times 25 \mathrm{kV}$ alternative? [autotransformer traction supply]. $50 \mathrm{kV}$ Autotransformer Traction Supply Systems - The French Experience, IEE Colloquium, pp. 1/1-1/4, 1993.

[3] Han, Z., Zhang, Y., Liu, S. \& Gao, S., Modeling and simulation for traction power supply system of high-speed railway. Power and Energy Engineering Conference (APPEEC), Wuhan, China, pp. 1-4, 2011.

[4] Richards, S.H., Application benefits of modern microprocessor distance protection for AC electrified railways. Sixth International Conference on Developments in Power System Protection (Conf. Publ. No. 434): Nottingham, UK, pp. 338-341, 1997.

[5] Zhou, Y., Xu, G. \& Chen, Y., Fault location in power electrical traction line system. Energies, 5, pp. 5002-5018, 2012. DOI: 10.3390/en5125002

[6] AREVA T\&D, Network Protection \& Automation Guide, Alstom Grid: UK, pp. 354-363, 2002.

[7] Han, Z., Liu, S., Gao, S. \& Bo, Z., Protection scheme for China high-speed railway. 10th IET International Conference on Developments in Power System Protection (DPSP 2010), Managing the Change, Manchester, pp. 1-5, 2010.

[8] Millard, A., Taylor, I.A. \& Weller, G.C., AC electrified railways-protection and distance to fault measurement. Proceedings of the 1995 International Conference on Electric Railways in a United Europe, Amsterdam, pp. 73-77, 1995.

[9] Wang, C. \& Yin, X., Comprehensive revisions on fault-location algorithm suitable for dedicated passenger line of high-speed electrified railway. IEEE Transactions on Power Delivery, 27(4), pp. 2415-2417, 2012. DOI: 10.1109/TPWRD.2012.2207270

[10] Xu, G., Zhou, Y. \& Chen, Y., Model-based fault location with frequency domain for power traction system. Energies, 6, pp. 3097-3114, 2013. DOI: 10.3390/en6073097

[11] Serrano, J., Platero, C.A., López-Toledo, M. \& Granizo, R., A novel ground fault identification method for $2 \times 25 \mathrm{kV}$ railway power supply systems. Energies, 8(7), pp. 7020-7039, 2015. DOI: $10.3390 /$ en 81010993 


\title{
LIFECYCLE VS ELEMENT COSTS: A NEW APPROACH TO OPTIMIZE THE POWER SUPPLY SYSTEM DESIGN IN RAILWAYS INFRASTRUCTURES
}

\author{
M. SOLER, J. LÓPEZ, J.M. MERA \& J. MAROTO \\ CITEF, Railway Technology Research Centre of the Universidad Politécnica de Madrid, Madrid, Spain.
}

\begin{abstract}
Electrification systems applied to railway systems have high complexity to achieve the optimum in several terms. These terms could be separated in energy supply and budget costs, such as direct and indirect costs, all of them derived from the implantation of the electrification system along the railway line. Starting from the experience in several projects carried out in CITEF (Railway Research Center in Technical University of Madrid), a new research way has grown up. The main goal has been an expert system, which is able to improve substantially the design process of power supply systems in railways, such as in AC as DC. Bearing in mind the specific constraints in terms of budget and electric standards, the expert system is able to determine a set of possible design scenarios. Each of them has the number, type and location for the main elements (catenary, substation, autotransformer, etc.). In this article a step forward is presented. This new step would apply a better way to choose between elements, hence taking into account the relationship between lifecycle versus element cost or losses avoided in the infrastructure. This has been applied to the main elements like traction substations, autotransformers, catenary and impact on maintenance and environmental zones. This new concept for evaluation has been integrated in the objective functions. These functions are the managers for the guidance of the optimization method, in this case genetic algorithm AMGA-II, in order to achieve the final Pareto Front. This Pareto Front contains the several possibilities which the designers must evaluate to accomplish their goals to power supply system.
\end{abstract}

Keywords: AMGA-II, life-cycle costs (LCC), maintenance and environmental zones, optimization, power supply design (PSD).

\section{INTRODUCTION}

The electrical system that supplies energy to the railway traction is a very complex system, which must achieve several important keys. Any power supply design (PSD) must include concepts such as electrical validation according to the standards, power demanded by trains of the operation plan, avoiding zones with high impact on environmental and maintenance zones, considering areas to connect with the general electric grid and finally budget of the project. The choice of the components and position through the line is a task which has been planned as a research way in several studies and works.

In CITEF a methodology has been developed during recent years. This methodology helps to find optimal solutions for the complex system explained before. The work developed by Soler et al. [1] is applied to the DC power supply using an expert system that helps in the choice about the PSD related to the railway traction. This expert system works with Hamlet Simulator [2] developed in CITEF and integrating a multi-objective genetic algorithm NSGAII [3]. The optimization algorithm from an initial configuration is able to converge to an optimum Pareto Front, which contains good proposals for the designer. The same research line 